\title{
Small RNA GcvB Regulates Oxidative Stress Response of Escherichia coli
}

\author{
Xian Ju ${ }^{1}$, Xingxing Fang ${ }^{1}$, Yunzhu Xiao ${ }^{1}$, Bingyu $\mathrm{Li}^{1,2}$, Ruoping Shi ${ }^{1}$, Chaoliang Wei ${ }^{2}$ and Conghui You ${ }^{1, *}$ \\ 1 Shenzhen Key Laboratory of Microbial Genetic Engineering, College of Life Sciences and Oceanology, \\ Shenzhen University, Shenzhen 518055, China; 2170257314@email.szu.edu.cn (X.J.); \\ fang_xing_xing@163.com (X.F.); xiaoyunzhu8891@163.com (Y.X.); byli@szu.edu.cn (B.L.); \\ srp642015142@163.com (R.S.) \\ 2 Health Science Center, Shenzhen University, Shenzhen 518055, China; weicl@szu.edu.cn \\ * Correspondence: cyou@szu.edu.cn
}

check for updates

Citation: Ju, X.; Fang, X.; Xiao, Y.; Li, B.; Shi, R.; Wei, C.; You, C. Small RNA GcvB Regulates Oxidative Stress Response of Escherichia coli. Antioxidants 2021, 10, 1774. https:// doi.org/10.3390/antiox10111774

Academic Editor: Nikolai

V. Gorbunov

Received: 14 October 2021

Accepted: 2 November 2021

Published: 5 November 2021

Publisher's Note: MDPI stays neutral with regard to jurisdictional claims in published maps and institutional affiliations.

Copyright: (C) 2021 by the authors. Licensee MDPI, Basel, Switzerland. This article is an open access article distributed under the terms and conditions of the Creative Commons Attribution (CC BY) license (https:/ / creativecommons.org/licenses/by/ $4.0 /)$.

\begin{abstract}
Small non-translated regulatory RNAs control plenty of bacterial vital activities. The small RNA GcvB has been extensively studied, indicating the multifaceted roles of GcvB beyond amino acid metabolism. However, few reported GcvB-dependent regulation in minimal medium. Here, by applying a high-resolution RNA-seq assay, we compared the transcriptomes of a wild-type Escherichia coli K-12 strain and its gcvB deletion derivative grown in minimal medium and identified putative targets responding to $\mathrm{GcvB}$, including $f l u$, a determinant gene of auto-aggregation. The following molecular studies and the enhanced auto-aggregation ability of the $g c v B$ knockout strain further substantiated the induced expression of these genes. Intriguingly, the reduced expression of OxyR (the oxidative stress regulator) in the $g c v B$ knockout strain was identified to account for the increased expression of $f l u$. Additionally, GcvB was characterized to up-regulate the expression of OxyR at the translational level. Accordingly, compared to the wild type, the GcvB deletion strain was more sensitive to oxidative stress and lost some its ability to eliminate endogenous reactive oxygen species. Taken together, we reveal that GcvB regulates oxidative stress response by up-regulating OxyR expression. Our findings provide an insight into the diversity of GcvB regulation and add an additional layer to the regulation of OxyR.
\end{abstract}

Keywords: Escherichia coli; small RNA; GcvB; oxidative stress; OxyR

\section{Introduction}

The Escherichia coli chromosome encodes more than 80 small non-translated regulatory RNAs [1] that control plenty of bacterial vital activities, including biofilm formation [2], transcription termination [3], cell signaling [4] and cellular responses to growth conditions of various factors of oxidative stress, osmolarities, temperature or iron levels [5-12].

The small RNA GcvB has been extensively studied since its discovery two decades ago [5]. GcvB is approximately $200 \mathrm{nt}$ in length and is highly conserved among Enterobacteriaceae [13,14]. GcvB expression is tightly related to glycine metabolism [15-19] and GcvA activates the transcription of GcvB [20] when glycine is abundant. Intriguingly, GcvB expression shows a strong growth condition-dependent feature. GcvB is abundant when cells are grown in rich medium during the exponential phase but is deficient when cells reach the stationary phase or are grown in minimal medium $[5,13,15,21]$. GcvB is depicted as a regulator of $1-2 \%$ of all the mRNAs in Salmonella Typhimurium and E. coli by using genome-wide experimental approaches including microarray [16] and RIL-seq [14], or by applying network [22] or in silico prediction [16,17]. Most of the known targets negatively regulated by GcvB are amino acid biosynthesis proteins and transporters of amino acids or peptides, as exampled by the two asparagine synthetases of AsnA and AsnB [21], the periplasmic transporter components of DppA and OppA [20], the serine/threonine transporter of SstT [23], and a certain amino acids transporter of CycA [15], suggesting 
the primary physiology role of GcvB could be to limit the uptake and biosynthesis of energy-expensive amino acid under nutrient-rich conditions [13,20]. In parallel, GcvB also negatively regulates the expression of several transcription factors including Lrp [24], a global regulator responding to the intracellular leucine level [25]; PhoP [26] in the PhoQP two-component system, which controls the expression of genes with functions in magnesium transport, acid resistance and lipopolysaccharide modification [27-29]; and CsgD [30], the master regulator of curli synthesis [31] Moreover, in a direct or an indirect mode, GcvB is positively involved in the acid stress response [32] and stress-induced DNA mutagenic break repair [33]. All this evidence indicates the relatively multifaceted roles of GcvB that are beyond amino acid metabolism.

In most cases, GcvB functions as a repressor. It blocks translational initiation by classically interfering with the $30 \mathrm{~S}$ ribosome subunit binding to a ribosome-binding site or inducing an active mRNA decay via the recruitment of ribonuclease $\mathrm{E}$ after pairing to the target mRNA [21]. GcvB also works as an activator. GcvB maintains the stability of the $r b n$ mRNA with the help of Hfq and protects it from RNase E cleavage [34]. GcvB up-regulates sigma factors RpoS [32] and RpoE [33], although the precise nature of the interactions between GcvB and these sigma factors is to be determined.

Therefore, there is diversity underlining both of the physiological roles and the molecular mechanisms of GcvB, which is worthy of further extensive exploration. Since people were unable to identify the GcvB-dependent regulation in minimal medium using traditional methods as promoter-lac $Z$ fusions $[15,20,21,23]$, possibly owing to the low expression of GcvB [21], in the present work, by applying the high resolution RNA-seq assay [35] that enabled us to largely expand the members in the regulons of several global regulators [36,37], we identified several novel targets putatively responding to GcvB in an E. coli K-12 strain grown in minimal medium. The subsequent molecular and physiological studies enabled us to discover that GcvB controlled the oxidative stress response of E. coli via the up-regulation of OxyR, the master regulator of antioxidant genes $[38,39]$. Thus, our findings not only provide insight into the diversity of GcvB regulation but also add an additional layer to the regulation of OxyR.

\section{Materials and Methods}

\subsection{Construction of Bacterial Strains and Plasmids}

All strains used in this work were derived from the wild-type E. coli K-12 strain NCM3722 [40] (GenBank acc. n: CP011496.1) and listed in Supplementary Table S1. Its derivatives of CY325 $(\Delta g c v B)$, CY1057 ( $\triangle$ oxyR::cat) and CY1042 ( $\Delta g c v B$ oxyR::cat) were constructed using the $\lambda$-Red system and the antibiotics markers were removed as described previously when necessary [41]. In aggregation-related experiments, since NCM3722 was unable to form flagella due to the defect of the flagella-structural protein FliC [42], the mutated fliC in NCM3722 was repaired to the wild-type fliC in MG1655 via P1 transduction to regain motility, resulting in the strain CY713. Then, its derivatives of the $g c v B$ knockout strain (CY1027) and the oxyR knockout strain (CY1038) were, respectively, constructed by the $\lambda$-Red system [41]. In order to detect OxyR using Western blot, the myc tag was, respectively, inserted right before the stop codon of the $o x y R$ gene in the $g c v B$ wild-type strain NCM3722 and in the $g c v B$ knockout strain CY325 by the $\lambda$-Red system [41], resulting in strains CY454 and CY455. To construct the oxyR promoter with lacZ fusion strains, at a first step, the $\operatorname{axy} R$ promoter region ( $-266 \mathrm{bp}$ to $+99 \mathrm{bp}$ relative to oxyR translational start point) was amplified from the genomic DNA of NCM3722 and was then inserted into the kpn I and Hind III sites of plasmid pCY161 (modified from pUC19 by adding an FRT-neo-FRT via EcoR I site), yielding plasmid pCY161-oxyR. Subsequently, the DNA regions of P1oxyR ( $-266 \mathrm{bp}$ to $+99 \mathrm{bp}$ relative to oxyR translational start point) or P2oxyR ( $-266 \mathrm{bp}$ to $+45 \mathrm{bp}$ relative to oxyR translational start point) together with the neo gene, was PCR amplified from the pCY161-oxyR plasmid and, respectively, integrated into the chromosome of the $g c v B$ wild-type strain CY1057 and the $g c v B$ knockout strain CY1042 to replace part of lacI and the entire lacZ promoter with the $5^{\prime} \mathrm{UTR}$ of lacZ (from $+134 \mathrm{bp}$ 
after lacI translational start codon to lacZ translational start codon) using the $\lambda$-Red system [41], resulting in the translational fusion strains CY1037 (P1oxyR in the $g c v B$ wild-type background), CY1041 (P1oxyR in the gcvB knockout background), CY1059 (P2oxyR in the gcvB wild-type background) and CY1060 (P2oxyR in the $g c v B$ knockout background), individually. P3oxyR ( $-266 \mathrm{bp}$ to $+0 \mathrm{bp}$ relative to $o x y R$ translational start point) was also PCR amplified from pCY161-oxyR and, respectively, integrated into the chromosome of CY1057 and CY1042 to replace part of lacI and the promoter of lacZ (from $+134 \mathrm{bp}$ after lacI translational start codon to lacZ transcriptional start site) using the $\lambda$-Red system [41], resulting in the transcriptional fusion strains of CY1047 (P3oxyR in the gcvB wild-type background) and CY1052 (P3oxyR in the gcvB knockout background). Note that we deleted the gene of oxy $R$ in all of the lac $Z$ fusion strains because oxyR expression was repressed by OxyR itself [43] and the LacZ activities of the oxyR promoters with the lac $Z$ fusions were hard to detect in the presence of the native oxyR.

\subsection{Growth of Cell Cultures}

Batch cultures were grown in either the $\mathrm{N}^{-} \mathrm{C}^{-}$minimal medium [40] supplied with $0.4 \%$ glucose and $20 \mathrm{mM} \mathrm{NH}_{4} \mathrm{Cl}$ or the $\mathrm{LB}$ rich medium. Batch culture growth in minimal medium was carried out in three steps in a $37^{\circ} \mathrm{C}$ water bath shaker as described previously [40]. Batch culture growth in LB rich medium was carried out in two steps in a $37^{\circ} \mathrm{C}$ water bath shaker: (1) Strains were firstly grown in LB overnight; (2) Then, they were diluted at a ratio of 1:100 for growth in LB of the experimental study. Cell samples were collected mid-exponential phase with an $\mathrm{OD}_{600} \sim 0.4$ for the following transcriptome study and RT-qPCR assay.

\subsection{RNA-Seq Assay and Analysis of Transcriptome Data}

Total RNA extraction and RNA-seq assay were performed as described previously [36]. Two independent total RNA extractions and transcriptome analyses by RNA-seq were performed for each NCM3722 and CY325 grown in glucose minimal medium. The DEGs between the two transcriptomes were characterized by edgeR $[q$-value (FDR) $<0.01$ and $|\log 2 \mathrm{FC}|>1$ ]. FPKM (Fragments Per Kilobase of transcript per Million mapped reads) [44] was used to calculate the expression of each gene.

\subsection{Quantitative Reverse Transcription PCR (RT-qPCR) Assay}

The total RNA of NCM3722 and CY325 were extracted, and cDNA templates were synthesized following the instruction of PrimeScript RT reagent Kit with gDNA Eraser (Takara, Beijing, China). RT-qPCR assays were performed on the qTOWER3 real-time PCR thermo-cycler (Analytik Jena, Jena, Germany). Primers for RT-qPCR were designed using Primer3 (v. 0.4.0) and listed in Supplementary Table S2. The gene of $r e c A$ was used as a reference control. The reaction mixture $(20 \mu \mathrm{L})$ consisted of $10 \mu \mathrm{L}$ of TB Green Premix Ex Taq II (Tli RNaseH Plus) (Takara, Beijing, China), $2 \mu \mathrm{L}$ of template (10-fold diluted cDNA), $7 \mu \mathrm{L}$ of $\mathrm{H}_{2} \mathrm{O}$ and $0.5 \mu \mathrm{L}(10 \mu \mathrm{M})$ of each primer. No template controls (NTC) were run in parallel, and all reactions were performed in triplicate. The relative quantification (RQ) was analyzed using the $\Delta \Delta \mathrm{Ct}$ quantification method by qPCRsoft v3.2, where CT refers to the cycle threshold.

\subsection{Aggregation Assay with Time-Lapse Microscopy}

E. coli cells were grown in $\mathrm{LB}$ to $\log$ phase with an $\mathrm{OD}_{600} \sim 0.4$. Cells were then collected by centrifugation ( $3 \mathrm{~min}, 6000 \mathrm{rpm}$ ) and resuspended in $\mathrm{LB}$ to a final $\mathrm{OD}_{600}$ of 0.1. Then, 2-milliliter cell suspensions were loaded into a 24-well polystyrene plate and cell clumps was also observed at $37^{\circ} \mathrm{C}$, using a phase-contrast microscopy (Nikon Ti2, Tokyo, Japan) with $20 \times$ objective lens and PH-20× -G eyepiece, which had a total $400 \times$ magnification effect. 


\subsection{Western Blot Assay}

Strains were grown in $\mathrm{LB}$ or glucose minimal medium to $\log$ phase with an $\mathrm{OD}_{600} \sim 0.4$. Cells were centrifuged at $6000 \mathrm{rpm}$ for $3 \mathrm{~min}$ and resuspended with $1 \times$ PBS. Then, $0.025 \mathrm{OD}_{600}$ or $0.05 \mathrm{OD}_{600}$ cells were mixed with M5 SDS-PAGE loading buffer (Mei5 biotechnology, Beijing, China) and then boiled for $10 \mathrm{~min}$. All the processed samples were added into SDS-PAGE gel and run at $120 \mathrm{~V}$ for approximately $120 \mathrm{~min}$. After running the gel, the protein on the gel was transferred to the PVDF (polyvinylidene fluoride) membrane (GE health care life science, Beijing, China) at $110 \mathrm{~V}$ for about $40 \mathrm{~min}$. Additionally, then the PVDF membrane was supposed to be immersed in $5 \%$ skimmed milk powder prepared from TBST ( $20 \mathrm{mM}$ Tris, $150 \mathrm{mM} \mathrm{NaCl}$ and $0.1 \%$ Tween-20) and shaken at room temperature for $3 \mathrm{~h}$. In this experiment, the selected internal reference protein was RpoB. Before incubating with different antibodies, the membrane was cut into two pieces according to the size of the protein and washed with TBST. The primary antibody (Monoclonal anti-RpoB antibody and Anti-Myc tag antibody) was added at a ratio of 1:2000 and was incubated with the membrane at room temperature for $2 \mathrm{~h}$ on a shaker. The secondary antibody (Goat anti-mouse lgG-HRP conjugated secondary antibody and Goat anti-rabbit $\operatorname{lgG}-H R P$ conjugated secondary antibody) was added at a ratio of 1:4000 and incubated with membranes at room temperature for $1.5 \mathrm{~h}$ on a shaker. SuperSignal West Pico PLUS (Thermo, Rockford, IL, USA) was applied for the exact purpose of imaging exposure. The image J was used for quantification analysis.

\section{7. $\beta$-Galactosidase Activity Assay}

Overnight culture of $E$. coli cells in LB were diluted at a ratio of 1:100 and grown in the same medium. At various $\mathrm{OD}_{600}(\sim 0.2-\sim 0.4)$ following the growth, three to five cell samples $(1 \mathrm{~mL})$ were quickly frozen in liquid nitrogen. Then, $0.025-0.5$-milliliter $(\mathrm{V})$ thawed samples were added into each tube and mixed with $0.975-0.5 \mathrm{~mL}$ of Z-buffer $\left(60 \mathrm{mM} \mathrm{Na}_{2} \mathrm{HPO}_{4}, 40 \mathrm{mM} \mathrm{NaH}_{2} \mathrm{PO}_{4}, 10 \mathrm{mM} \mathrm{KCL}\right.$ and $1 \mathrm{mM} \mathrm{MgSO}$ ), containing BME ( $\beta$-Mercaptoethanol) to be a total reaction volume of $1 \mathrm{~mL}$. One blank reaction with solely $1 \mathrm{~mL}$ of Z-buffer was set. Additionally, $25 \mu \mathrm{L}$ of $0.1 \%$ SDS and $50 \mu \mathrm{L}$ of chloroform were added into the commixture. After incubating these tubes in the $37^{\circ} \mathrm{C}$ water bath for $5 \mathrm{~min}$, at time $\mathrm{T}_{0}, 200 \mu \mathrm{L}$ of $4 \mathrm{mg} / \mathrm{mL}$ ONPG (o-Nitrophenyl $\beta$-D-galactopyranoside) were added into each mixture and incubated in the water bath at $37^{\circ} \mathrm{C}$. When the color of the reaction turned yellow at time $\mathrm{T}_{1}$, we stopped the reaction by adding $1 \mathrm{M} \mathrm{Na}_{2} \mathrm{CO}_{3}$. The reaction time $\mathrm{T}=\mathrm{T}_{1}-\mathrm{T}_{0}(\mathrm{~min})$. Finally, $1 \mathrm{~mL}$ of reaction sample was centrifuged at 13,000 rpm for $5 \mathrm{~min}$ and the $\mathrm{OD}_{420}$ and $\mathrm{OD}_{550}$ were measured. The $\beta$-galactosidase activity in miller unit $\left(\mathrm{U} / \mathrm{mL} / \mathrm{OD}_{600}\right)$ was calculated as $1000 \times\left(\mathrm{OD}_{420}-1.75 \times \mathrm{OD}_{550}\right) / \mathrm{V} / \mathrm{T}$.

\subsection{Assay of Bacterial Resistance to $\mathrm{H}_{2} \mathrm{O}_{2}$ Treatment}

Overnight cultures of the strains in LB were diluted at a ratio of 1:100 in the same medium and cultured to an exponential phase. Subsequently, the cultures were individually diluted to an $\mathrm{OD}_{600}$ of 0.05 and treated with $3 \mathrm{mM} \mathrm{H}_{2} \mathrm{O}_{2}$. Then, the $\mathrm{OD}_{600}$ of each culture was measured. For survival assay, bacterial cells grown in LB from early exponential phase $\left(\mathrm{OD}_{600}\right.$ of $\sim 0.4$ ) were exposed to $20 \mathrm{mM} \mathrm{H}_{2} \mathrm{O}_{2}$ for $10 \mathrm{~min}$ and plated on LB plates by series dilution. The survival rate was calculated by colony counting.

\subsection{Microscopic Detection of Reactive Oxygen Species (ROS)}

NCM3722 and CY325 were incubated overnight in $2 \mathrm{~mL}$ of LB, after which they were diluted at a ratio of 1:100 into LB and grown to log phase with an $\mathrm{OD}_{600}$ of $\sim 0.4$. Additionally, $1 \mathrm{~mL}$ of cell culture of each strain was harvested by centrifugation and resuspended into $1 \mathrm{~mL}$ of sterile PBS. Then, $10^{8}$ cells $/ \mathrm{mL}$ were collected and incubated with $150 \mu \mathrm{M}$ DHE and $\mathrm{H}_{2}$ DCFDA for $90 \mathrm{~min}$ in darkness with rotation at $37^{\circ} \mathrm{C}$. After staining, the bacteria were centrifuged at $6000 \mathrm{rpm}$ for $3 \mathrm{~min}$ at room temperature and washed with the same volume of warm sterile PBS. Finally, a cell density of approximately $2 \times 10^{7}$ cells $/ \mathrm{mL}$ was adjusted for microscopic observation. Cells were observed at $37^{\circ} \mathrm{C}$ 
with a phase-contrast microscopy (Nikon Ti2, Tokyo, Japan). A $20 \times$ objective lens and $\mathrm{PH}-20 \times-\mathrm{G}$ eyepiece were applied for observing phase-contrast cells. A 450-nanometer laser was used for excitation and a band-pass filter of $610 \mathrm{~nm}$ was used to collect the red fluorescence. A 480-nanometer laser was used for excitation and a band-pass filter of $535 \mathrm{~nm}$ was used to collect the green fluorescence. Fluorescence intensity of each cell was quantified using the software of Nikon NIS-Elements AR.

\section{Results}

\subsection{The Expression of Flu Was Highly Induced in the gcoB Deletion Strain}

To characterize the putative target genes controlled by the small RNA GcvB (GenBank acc. n: CP011496.1, region 4,184,713-4,184,917), we compared the transcriptomes of the wild-type E. coli K-12 strain NCM3722 and its gcvB deletion derivative CY325 grown in glucose minimal medium by high resolution RNA-seq [35]. We first found that both the $\operatorname{gcv} B$ deletion and wild-type strains showed similar doubling times in the glucose minimal medium, indicative of a relatively limited role of $\mathrm{GcvB}$ regulation in this condition (Supplementary Figure S1). In total, five genes were retained as significant with a twofold cutoff (with an FDR smaller than 0.01) (Figure 1A, Supplementary Table S3) in the transcriptome study. Compared to their expression in NCM3722, the genes of $f l u$ (GenBank acc. n: CP011496.1, region 3,331,422-3,334,541) and yeeR (GenBank acc. n: CP011496.1, region 3,334,662-3,336,223) exhibited highly increased expression in CY325, respectively, showing a fold change of 63.6 and 4.6, whereas the remaining three genes showed an approximately two-fold decreased expression in CY325. Since $f l u$ and yeeR showed the biggest fold of expression changes, we further tested their expression in the two strains using the RT-qPCR assay. Consistent with the RNA-seq data, the mRNA levels of $f l u$ and yeeR in CY325 were significantly higher than that in the wild type when cells were grown in glucose minimal medium (Figure 1B,C). Similar results were also observed when cells were grown in LB rich medium (Figure 1D,E). Thus, flu and yeeR could be negatively regulated by GcvB in a direct or an indirect mode.

In the genome of NCM3722, the gene of $f l u$ localized right upstream of the gene of yee $R$ in the same DNA strand. The gene of yeeR is a pseudogene and the gene of $f l u$ encodes antigen 43 (Ag43). Ag43 is an abundant outer membrane protein that belongs to the auto-transporter family and is a major determinant of auto-aggregation in E. coli [45,46]. Thus, we studied the auto-aggregation of both the $g_{c v B} B$ knockout and wild-type strains. As reported, bacterial motility and chemotaxis were required for the Ag43-dependent aggregation of E. coli [46]. However, the two strains applied in the transcriptome study were non-motile [47] because the flagellar filament structural protein [48] encoded by fliC (GenBank acc. n: CP011496.1, region 3,261,993-3,263,489) carries a lone mis-sense mutation (N87K) [42]. We complemented the mutated fliC of NCM3722 to the wild-type fliC to obtain the motile strain CY713, and the gene of $g c v B$ was deleted in CY713 to obtain the gcvB knockout strain CY1027. Consequently, the auto-aggregation ability of CY713 and CY1027 was then compared using microscopy. Indeed, we observed that the $g c v B$ knockout strain CY1027 aggregated more efficiently than the $g c v B$ wild-type strain CY713 (Figure 2), supporting the highly induced $f l u$ expression in the gcvB knockout strain. 
(A)

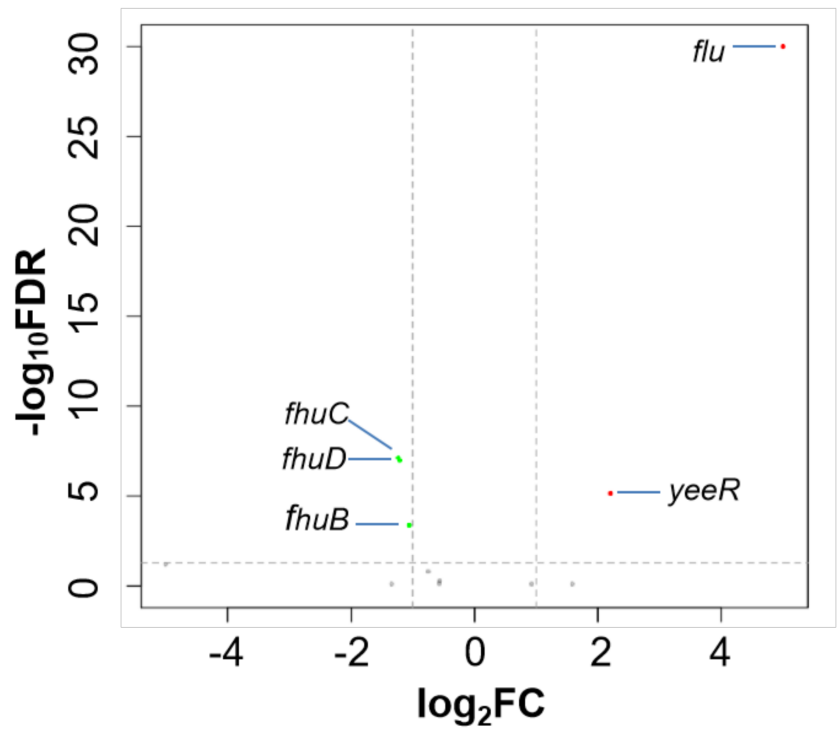

(B)

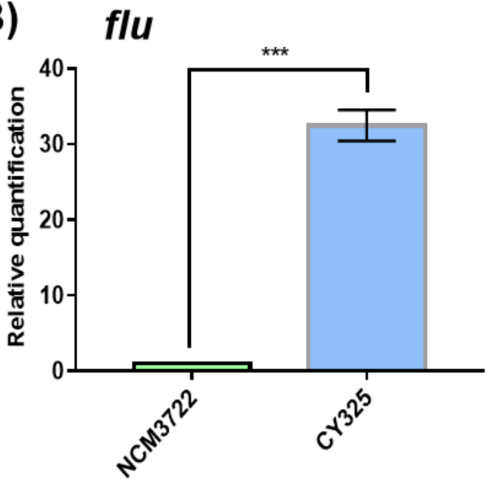

(D)

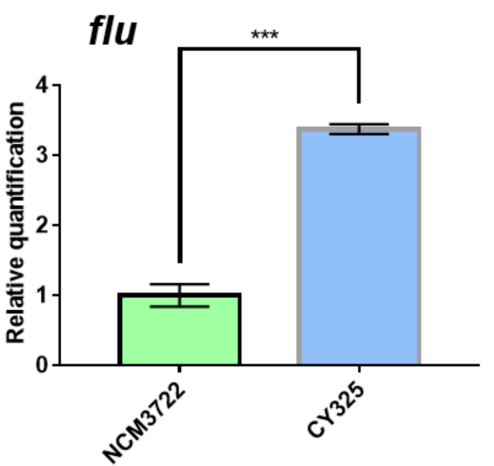

(C)

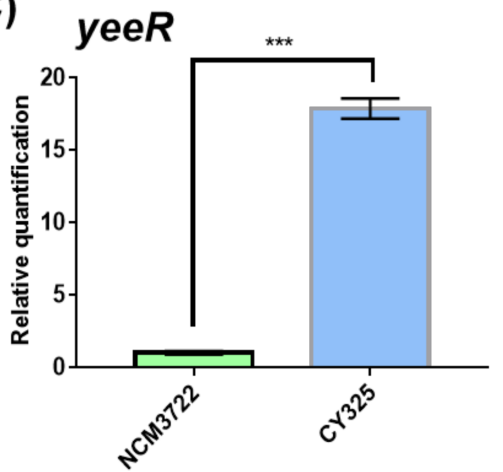

(E)

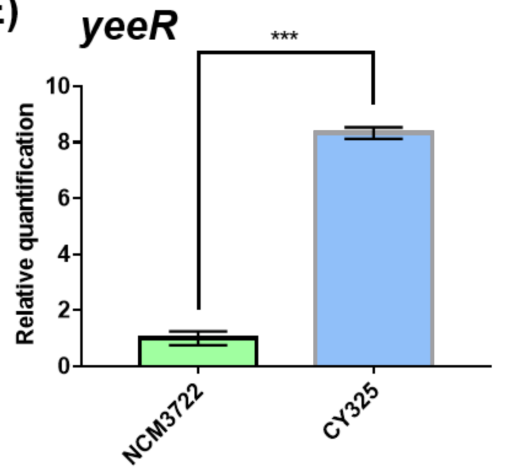

Figure 1. Genes responding to GcvB. (A) Volcano map comparing the expression of genes in the gcvB knockout strain CY325 versus that in the wild-type strain NCM3722. The horizontal dashed line points to $q$-value $(\mathrm{FDR})=0.01$ on $y$-axis and the vertical dashed lines point to 2 -fold cutoff of the expression on $x$-axis. Red dots indicate up-expressed genes; green dots indicate down-expressed genes; grey dots indicate genes showed no significant changes. Note that the data points of the remaining genomic genes carrying a $q$-value $(\mathrm{FDR})=1$ with a corresponding $-\log _{10} \mathrm{FDR}=0$ were not shown. (B,E) Gene expression of $f l u$ and yeeR detected using RT-qPCR in the $g c v B$ knockout strain CY325 and in the wild-type strain NCM3722 grown in glucose minimal medium (B,C) or in LB rich medium (D,E). The mRNA level of each gene in NCM3722 was normalized to 1 and that in CY325 was determined relative to this value. The relative expression was shown as the average \pm S.D. of three independent experiments. ${ }^{* * *} p<0.001$ using Student's $t$-test. 


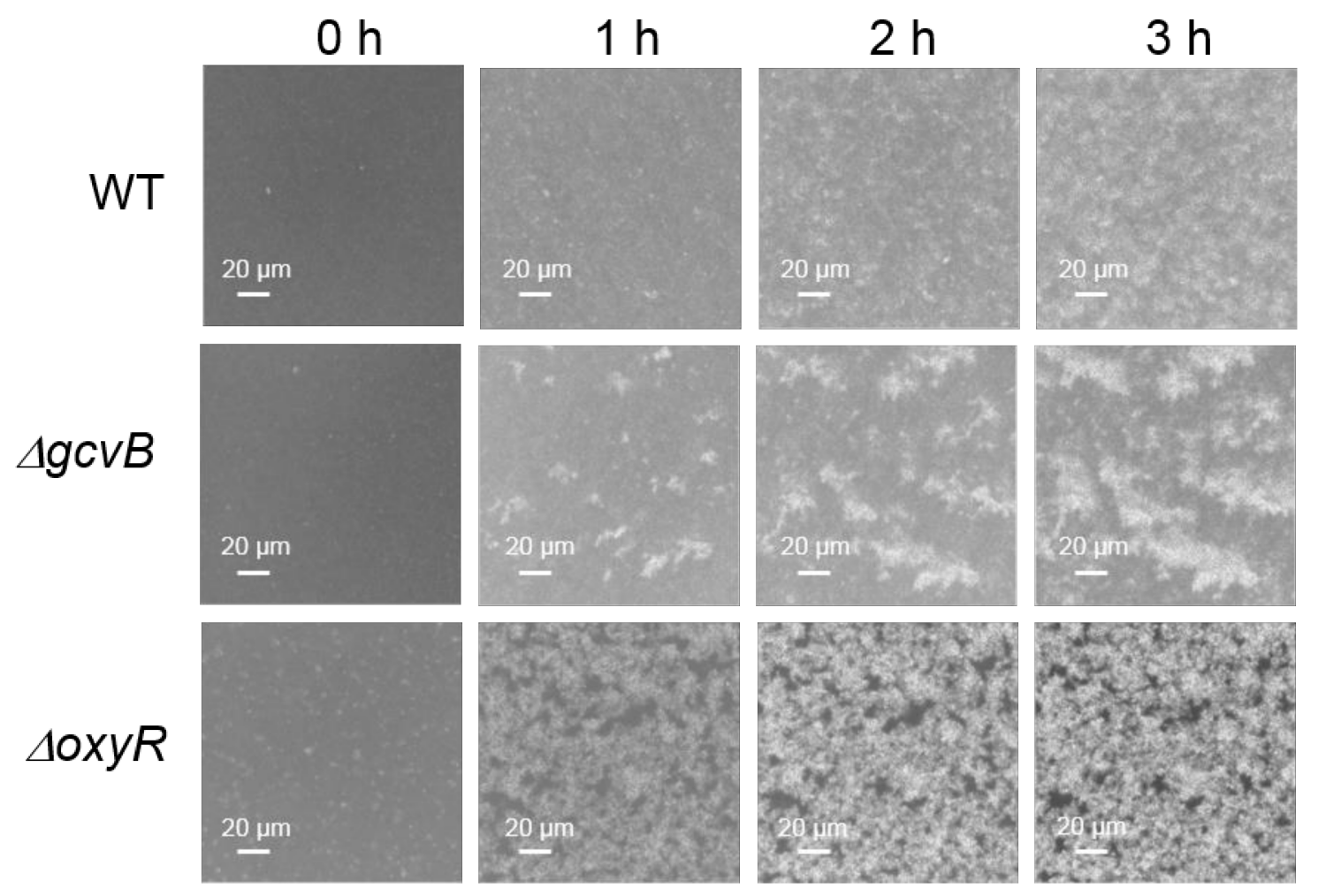

Figure 2. Aggregation assays of three E. coli strains. The aggregation of CY713 (WT), CY1027 (gcvB::cm) and CY1038 $\left(\right.$ oxyR:: $\mathrm{cm}$ ) was detected at $37{ }^{\circ} \mathrm{C}$ into a 24-well polystyrene plate using microscopy as described in methods. Bacterial aggregation was monitored at various time points $(0-3 \mathrm{~h})$. The formation of the white cluster indicates aggregation of cells. One representative result of two independent observations is shown.

\subsection{OxyR Showed Decreased Expression in the gcoB Deletion Strain}

As reported, the transcription of $f l u$ was repressed by OxyR [49]. Accordingly, we identified the highly induced expression of $f l u$ in the oxyR (GenBank acc. n: CP011496.1, region 736,030-736,947) deletion strain (Supplementary Figure S2A). In parallel, the oxyR deletion strain was observed to exhibit the high auto-aggregation efficiency (Figure 2) indicative of the highly expressed flu. Moreover, we monitored the expression of yeeR in the oxyR deleted background and found that yeeR showed a similar induced expression as $f l u$ (Supplementary Figure S2B). Given their congruent responses and their concatenated locations in the genome, it was very likely that $f l u$ and yeeR formed an operon and both were under the control of OxyR.

Thus, the protein levels of OxyR in the $g c v B$ knockout and wild-type strains grown in the LB rich medium or the glucose minimal medium were determined using Western blot. We identified that the protein amount of OxyR in CY455 $(\triangle g c v B)$ was approximately half that in the $g_{c v B}$ wild-type strain CY454 in both conditions (Figure 3). As a result, the decreased expression of the OxyR repressor in the $g c v B$ knockout strain could induce the high expression of $f l u$. 
(A)

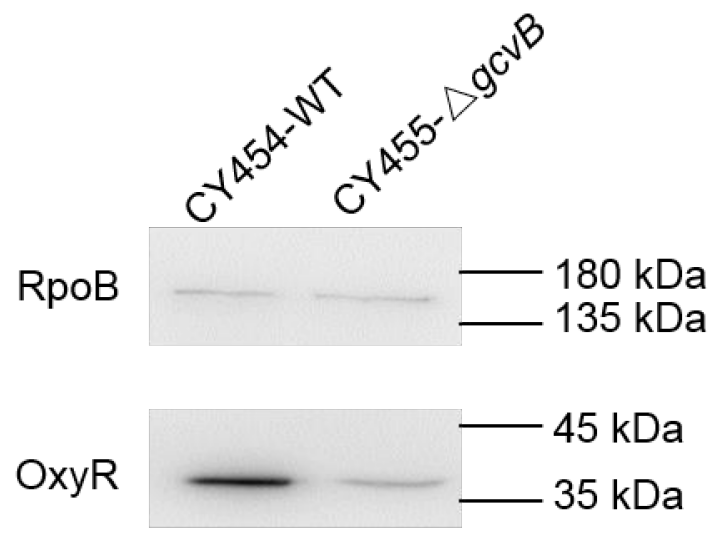

(B)

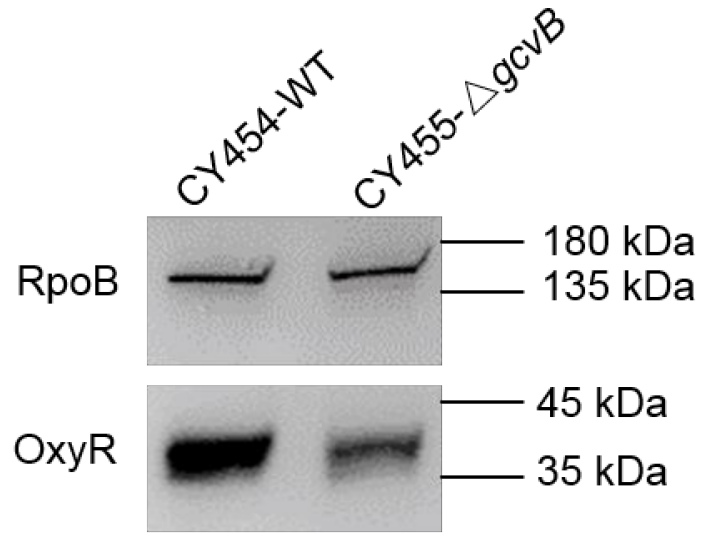

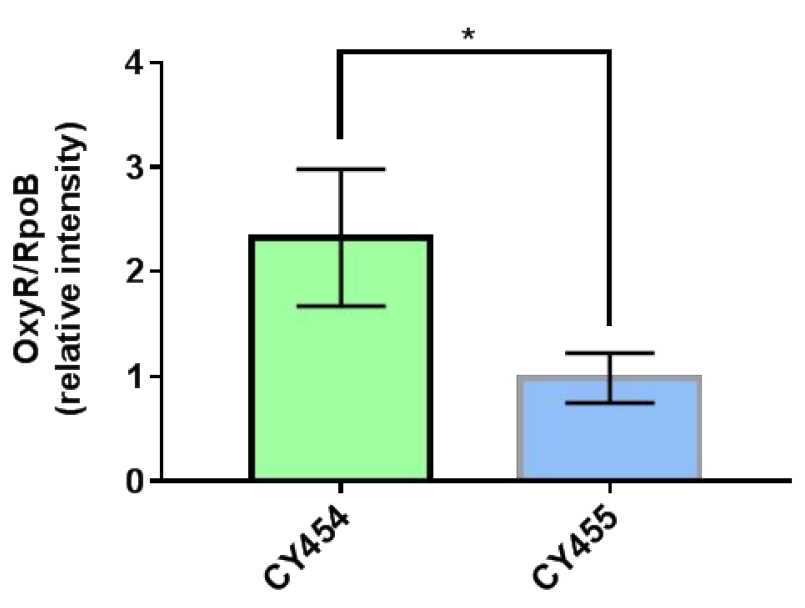

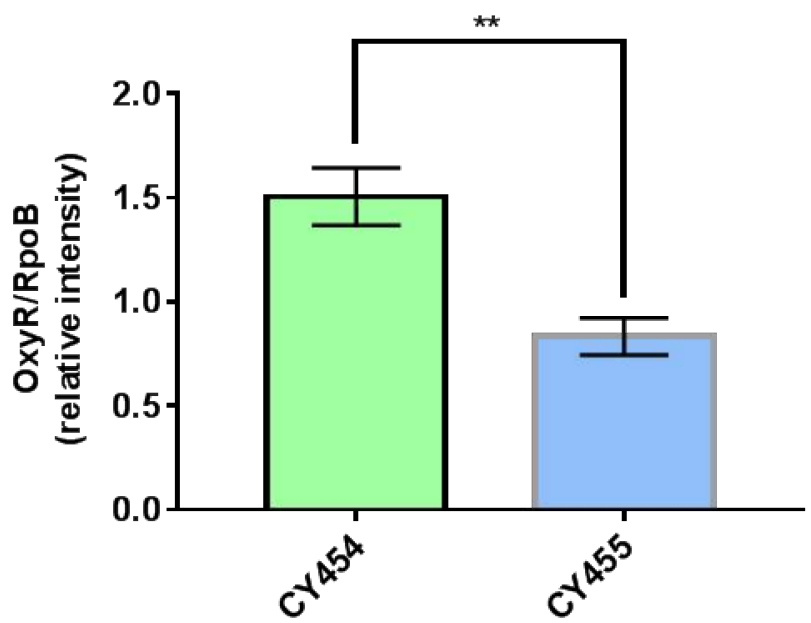

Figure 3. The protein levels of OxyR in the $g c v B$ knockout and wild-type strains. The protein levels of OxyR in the $g c v B$ wild-type strain CY454 and in the gcvB knockout strain CY455 cultured in LB rich medium (A) or in glucose minimal medium (B) were tested using Western blot. RpoB was applied as a loading control. The $0.025 \mathrm{OD}_{600}(\mathbf{A})$ or $0.05 \mathrm{OD}_{600}$ (B) cells were loaded. One representative result of six repeats in two independent Western blots is shown on the left. The relative protein level of three repeats in one Western blot is shown as the average \pm S.D. on the right. The protein level of OxyR in CY455 was normalized to 1 and that in CY454 was determined relative to this value. ${ }^{* *} p<0.01,{ }^{*} p<0.05$ using Student's t-test.

\subsection{The Small RNA GcvB Enhanced the Expression of OxyR at the Translational Level}

We next explored how GcvB stimulated the expression of OxyR. The mRNA level of $\operatorname{oxyR}$ did not show significant changes in the two transcriptomes of the $g c v B$ wildtype and knockout strains (Supplementary Figure S3A) and this finding was further demonstrated using the RT-qPCR assay (Supplementary Figure S3B). Moreover, we made an oxyR promoter with lacZ transcriptional fusion (Supplementary Figure S3C) in both the gco $B$ wild-type and knockout strains and observed that the $\beta$-galactosidase activity showed no significant changes in the two backgrounds (Supplementary Figure S3D). As a result, it was most likely that the regulation of GcvB on OxyR existed at the post-transcriptional level. To substantiate this hypothesis, we constructed the oxyR promoter with lac $Z$ translational fusions in both the $g c v B$ wild-type and knockout strains. We made two fusion constructions, with P1 and P2, respectively, carrying 99 and $45 \mathrm{nt}$ after the translational start codon of oxyR (Figure 4A). Supporting the Western blot result (Figure 3), both translational fusions 
showed significantly decreased $\beta$-galactosidase activity in the $g c v B$ knockout strain when being compared to that in the $g c v B$ wild-type strain (Figure $4 B, C$ ), indicating GcvB activated the expression of OxyR at the translational level.

\section{(A)}
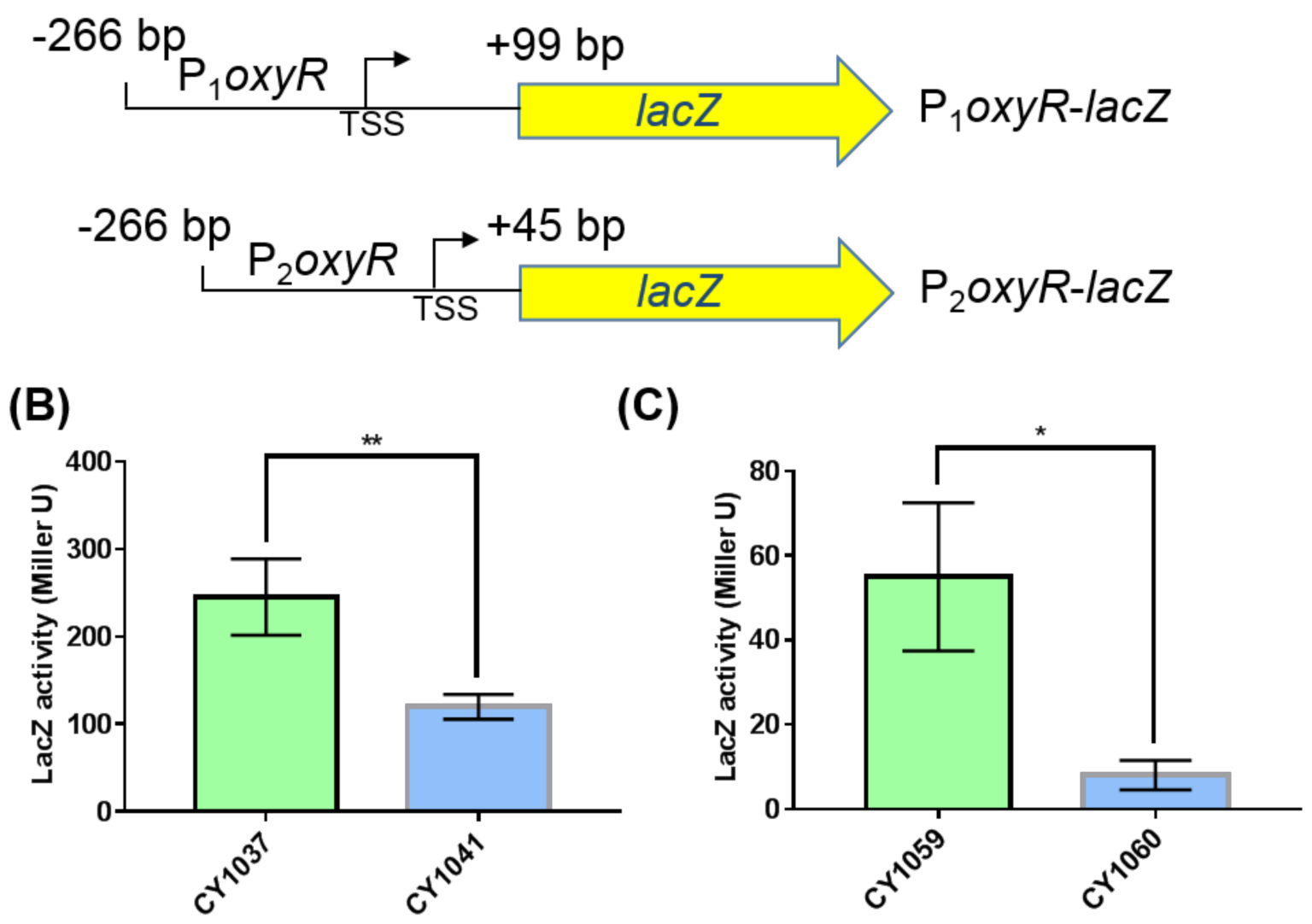

Figure 4. $\beta$-galactosidase activities of the $o x y R$ promoter with lacZ translational fusions in the $g c v B$ knockout and wild-type strains. (A) Composition diagrams of the promoters of $o x y R$ with lac $Z$ translational fusions. $P_{1}$ oxyR covers the DNA region from $-266 \mathrm{bp}$ to $+99 \mathrm{bp}$ relative to oxyR translational start point and $\mathrm{P}_{2}$ oxyR covers the DNA region from $-266 \mathrm{bp}$ to +45 bp relative to oxy $R$ translational start point. Yellow arrow indicates the entire coding region of lacZ. TSS indicates the transcriptional start site of $o x y R$. (B) $\beta$-galactosidase activities of $\mathrm{P}_{1} \mathrm{oxyR}$-lacZ fusion in the gcvB wild-type (CY1037) and knockout strains (CY1041). (C) $\beta$-galactosidase activities of $P_{2}$ oxyR-lacZ fusion in the gcvB wild-type (CY1059) and knockout strains (CY1060). The LacZ activity was shown as the average \pm S.D. of three independent experiments. ${ }^{* *} p<0.01$, * $p<0.05$ using Student's $t$-test.

\subsection{The gcoB Deletion Strain Was Sensitive to Oxidative Stress}

Since OxyR is the transcriptional regulator that induces the expression of antioxidant genes in response to oxidative stress [38,39], the reduced expression of OxyR when $g c v B$ was deleted suggested that the $g c v B$ deletion strain could be sensitive to oxidative stress. Therefore, we tested the response of the $g c v B$ wild-type and knockout strains to oxidative stress. Indeed, when additional $\mathrm{H}_{2} \mathrm{O}_{2}$ was supplied to the growth medium, the $g c v B$ mutant grew more slowly and showed less resistance to $\mathrm{H}_{2} \mathrm{O}_{2}$ than the gcvB wild-type strain (Figure 5A). Moreover, we also tested the response of the oxyR deletion strain to $\mathrm{H}_{2} \mathrm{O}_{2}$ treatment. As expected, the oxyR deletion strain was sensitive to the oxidative stress. In the same line, both the $g c v B$ and the oxyR mutants showed significantly lower survival rates than the wild type in the survival assay (Figure 5B). 
(A)

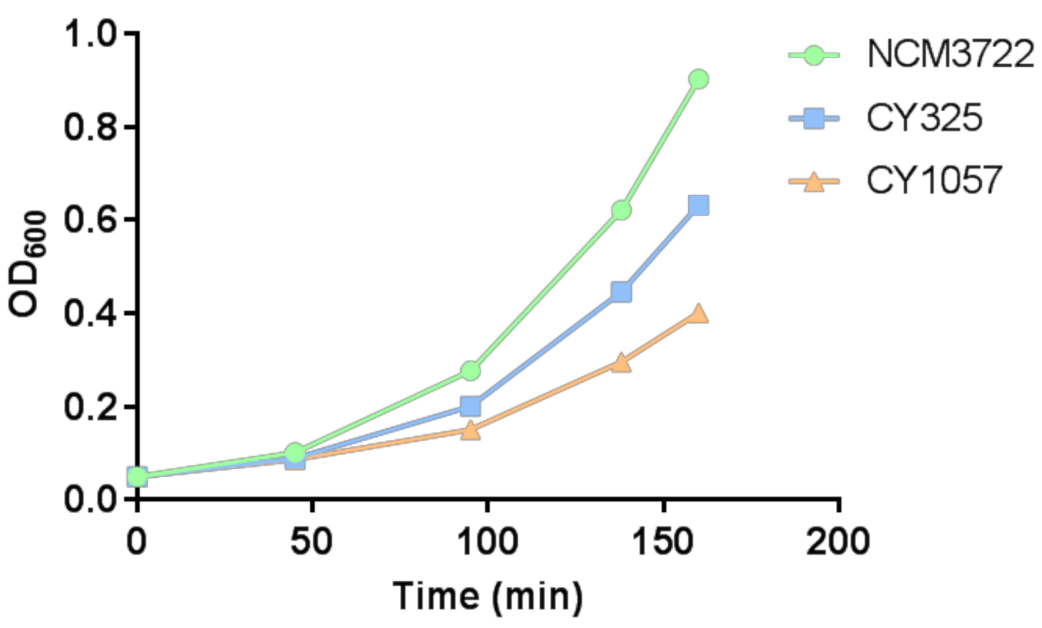

(B)

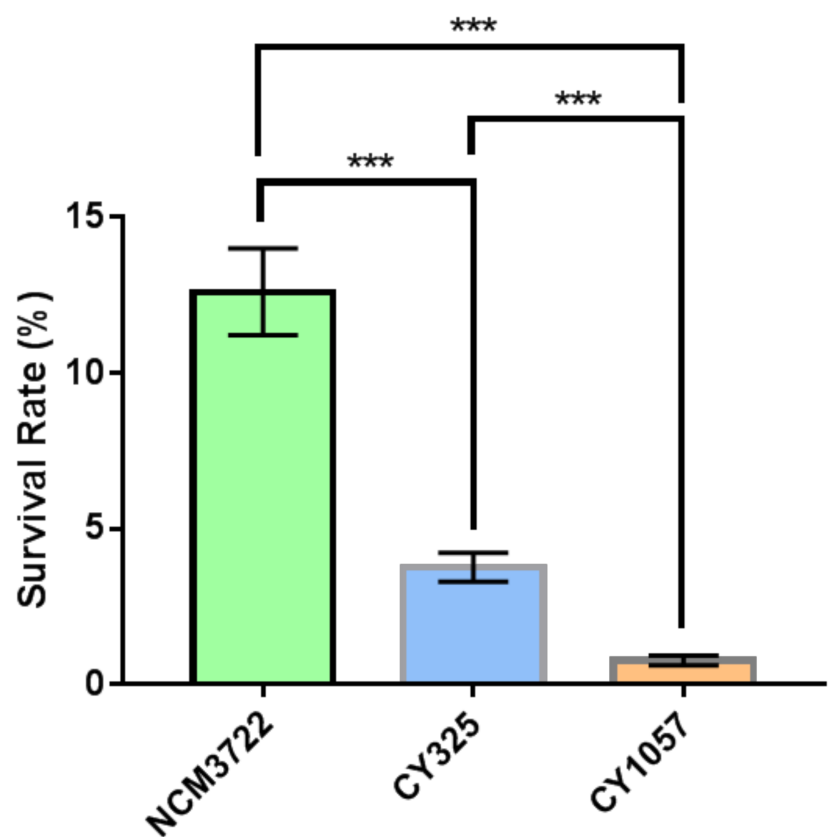

Figure 5. The sensitivity of the $g c v B$ deletion strain to oxidative stress. (A) The growth of strains with $\mathrm{H}_{2} \mathrm{O}_{2}$ supplied to the medium. The growth curve of each strain was recorded after $3 \mathrm{mM} \mathrm{H}_{2} \mathrm{O}_{2}$ was supplied into the growth medium. One representative result of three independent experiments is shown. NCM3722 (WT); CY325 ( $\Delta g c v B)$; CY1057 ( $\Delta$ oxyR). (B) Survival rate of the three strains after a 10-minute challenge of $20 \mathrm{mM} \mathrm{H}_{2} \mathrm{O}_{2}$. The survival rate is shown as the average \pm S.D. of the six replicates in two independent experiments. ${ }^{* *} p<0.001$ using Student's $t$-test.

The endogenous ROS were generated as byproducts of aerobic respiration [50]. Given the decreased expression of OxyR in the $g c v B$ mutant, the $g c v B$ mutant could accumulate more endogenous ROS. To verify this point, using fluorescence microscopy, we monitored the intracellular amount of ROS that remained in the $g_{c v B}$ wild-type and knockout strains by employing two kinds of ROS indicators, DHE (dihydroethidium) and $\mathrm{H}_{2}$ DCFDA $\left(2^{\prime}, 7^{\prime}\right.$ dichloro-dihydro-fluorescein diacetate), both of which are membrane-permeant dyes that can be oxidized to show red and green fluorescence, respectively, and have been widely 
used as fluorescence probes for the detection of superoxide and peroxide due to their specificity to these radicals [51]. The phase contrast and fluorescence micro-photographs of the two strains stained with DHE and $\mathrm{H}_{2}$ DCFDA were exhibited (Figures 6A and 7A). Compared to the $g c v B$ wild-type cells, larger numbers of $g c v B$ knockout cells showed stronger fluorescence using both indicators indicative of higher levels of ROS remaining in the $g_{c v} B$ knockout cells. The mean fluorescence intensity of CY325 cells, respectively, stained with DHE or $\mathrm{H}_{2}$ DCFDA was approximately two- to six-fold stronger than that of NCM3722 cells (Figures 6B and 7B). These observations suggested that, compared to the $g c v B$ wild-type cells, the $g c v B$ knockout cells could lose some of their ability to eliminate endogenous ROS where the expression of OxyR was reduced.

(A)

Phase contrast

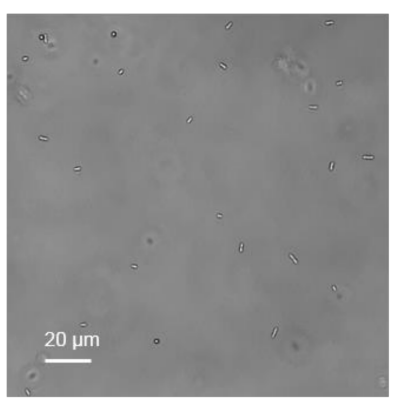

$\Delta g c v B$

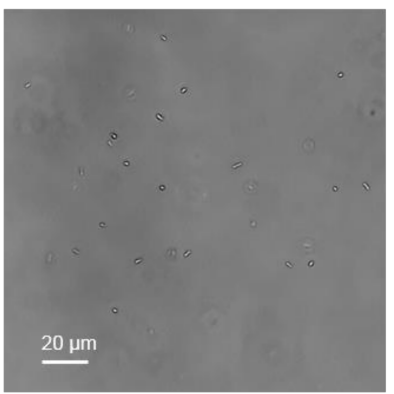

Fluorescence
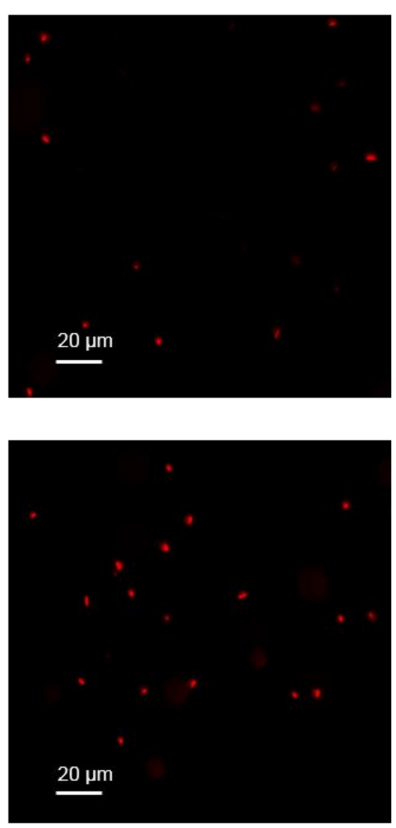

(B)

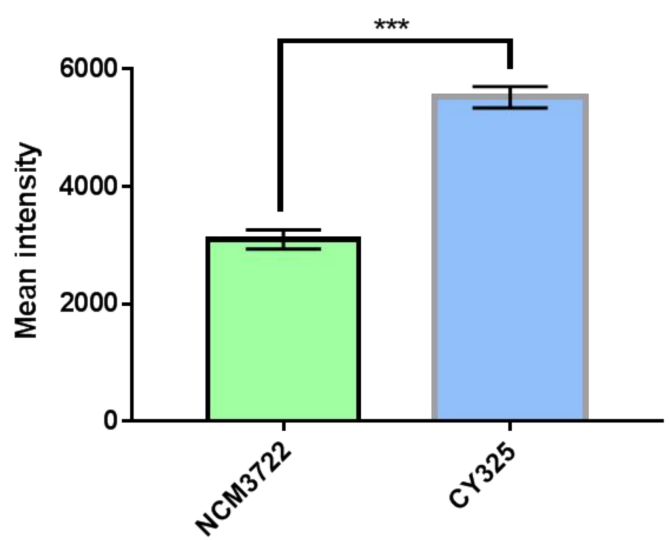

Figure 6. Detection of superoxide. (A) Detection of superoxide by DHE staining. The phase contrast shows the cells under microscope and the red fluorescence represents the detection of superoxide. Two to three independent observations were performed and one image containing representative cells is shown. (B) Quantification of fluorescence intensity. Fluorescence intensity was expressed as the average \pm S.E.M., calculated from 393 to 416 individual cells. NCM3722 (WT); CY325 ( $\Delta g c v B)$. *** $p<0.001$ using Student's $t$-test. 
(A)

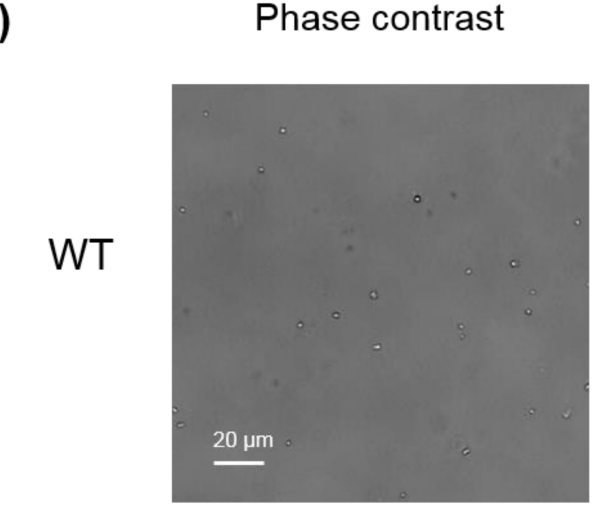

$\Delta g c v B$

(B)

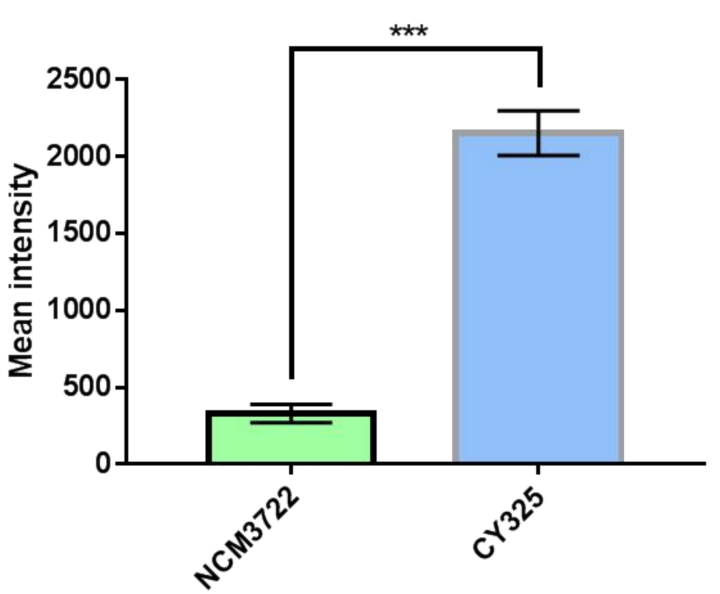

Fluorescence
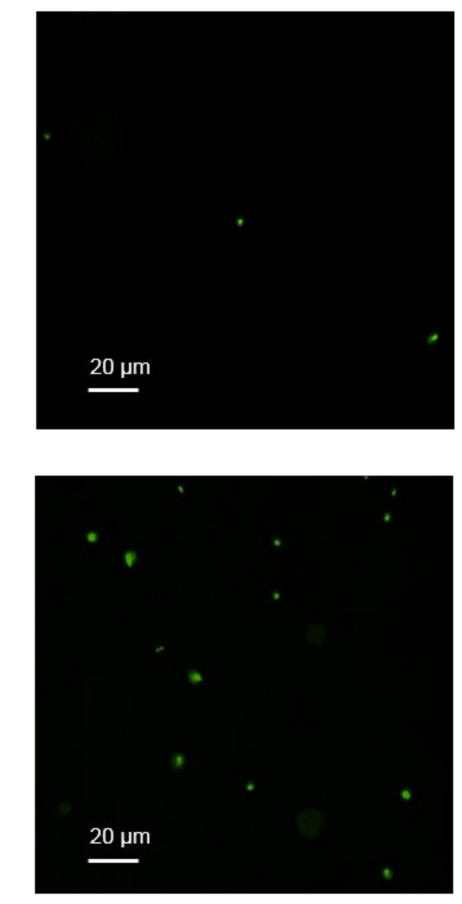

$20 \mu \mathrm{m}$

$\underline{20 \mu m}$

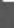

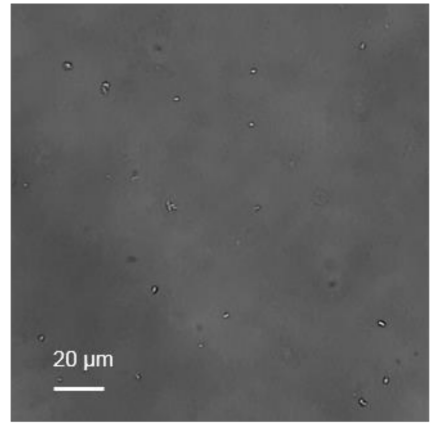

Figure 7. Detection of peroxide. (A) Detection of peroxide by $\mathrm{H}_{2}$ DCFDA staining. The phase contrast shows the cells under microscope and the green fluorescence represents the detection of peroxide. Two to three independent observations were performed and one image containing representative cells is shown. (B) Quantification of fluorescence intensity. Fluorescence intensity was expressed as the average \pm S.E.M., calculated from 468 to 741 individual cells. NCM3722 (WT); CY325 ( $\Delta g c v B)$. *** $p<0.001$ using Student's $t$-test.

\section{Discussion}

In this study, we performed comparative transcriptomes combined with molecular and physiological studies of the GcvB knockout and wild-type strains to characterize the putative target genes controlled by the small RNA GcvB. In this process, we were able to identify GcvB as a positive regulator controlling the oxidative stress response of E. coli.

GcvB-dependent regulation on its known targets in glucose minimal medium was almost undetectable using a traditional method [15], possibly because of the low expression 
of GcvB in this medium when being compared to its expression in rich medium [21]. In contrast, here, we characterized novel targets putatively controlled by GcvB in the minimal medium by applying the high-resolution RNA-seq assay that had helped us to successfully expand the members in the regulons of several global regulators [36,37]. Note that we also did not find the reported targets of GcvB in this medium, which is inconsistent with previous results.

We firstly found that the expression of $f l u$ and yeeR was highly induced when GcvB was deleted by the transcriptome study (Figure 1A), indicating that GcvB could negatively regulate their expression in a direct or indirect mode. Our following RT-qPCR studies (Figure 1B-E) and the enhanced flu-dependent auto-aggregation ability [45] of the gcvB knockout strain (Figure 2) further substantiated the induced expression of these genes.

We next explored the putative mechanisms of the small RNA GcvB repressed expression of $f l u$ and yeeR. It is well known that small RNA can regulate gene expression by controlling mRNA stability [52]. Consequently, GcvB could control the expression of $f l u$ and yeeR by regulating their mRNA stability as in the cases of its reported targets [21]. However, we found that $f l u$ and yeeR could form an operon since $f l u$ and yeeR were concatenated genes in the genome and they showed congruent expression changes in the conditions we studied (Figure 1 and Figure S2). To our knowledge, it was rare that a small RNA simultaneously regulated the expression of individual genes in one operon. As a result, it was more likely that $\mathrm{GcvB}$ controlled the expression of $f l u$ and yeeR in an indirect mode. Additionally, a mediator would coordinate the regulation of GcvB on $f l u$ and yeeR. Since OxyR, the oxidative stress regulator [38,39], is the reported transcriptional repressor of $f l u$ [49], this motivated us to study OxyR. Similar to $f l u$, yeeR also responded to OxyR (Supplementary Figure S2). Intriguingly, we identified that GcvB positively controlled the expression of OxyR (Figure 3), and this regulation existed at the translational level (Figure 4). Thus, OxyR could be the mediator and its reduced expression in the $g c v B$ knockout strain could induce the high expression of $f l u$ and yeeR. However, further detailed studies will be required to investigate the nature of the interaction between GcvB and OxyR at the molecular level.

Finally, our physiological studies supported the positive regulation of GcvB on OxyR since the GcvB deletion strain was not only more sensitive to external oxidative stress (Figure 5) but also lost some of its ability to eliminate endogenous ROS when being compared to the wild type (Figures 6 and 7). Thus, the reduced expression of OxyR could account for these phenomena observed. However, except $f l u$, we did not identify the other reported targets of OxyR [49] that showed significant expression changes between the GcvB wild-type and knockout strains using the RNA-seq assay, possibly because their expression changes could be small, thus, were below the detection limit of this method. Consequently, the OxyR regulon gene of $f l u$ could be the one that was most sensitive to the titration of OxyR. Moreover, it was proposed that the sensibility of bacteria to antibiotics was correlated to the endogenous production of ROS [53]. Therefore, the enhanced ROS levels in the $g_{c v} B$ knockout strain could make this strain more sensitive to antibiotics treatment and GcvB could accordingly work as a putative antimicrobial target.

\section{Conclusions}

By integrating a global assay with molecular and physiological studies, we reveal a novel function of the small RNA GcvB. GcvB enhances the survival ability of E. coli when experiencing oxidative stress by the up-regulation of OxyR expression. Our findings provide insight into the control of the oxidative stress response of E. coli by GcvB and add an additional layer to the regulation of OxyR.

Supplementary Materials: The following are available online at https://www.mdpi.com/article/10 .3390/antiox10111774/s1, Figure S1: Doubling times of NCM3722 (WT) and CY325 ( $\triangle$ gcvB) grown in glucose minimal medium, Figure S2: Gene expression of $f l u$ and yeeR in the oxyR wild-type and knockout strains, Figure S3: Transcriptional expression of $o x y R$. Table S1: Strains used in this work, 
Table S2: Primers used for RT-qPCR, Table S3: DEGs identified between the $g c v B$ knockout and wild-type strains.

Author Contributions: Conceptualization, C.Y. and X.J.; methodology, X.J. and X.F.; formal analysis, X.J. and X.F.; investigation, X.J., X.F., Y.X., B.L., R.S. and C.W.; data curation, X.J. and X.F.; writingoriginal draft preparation, C.Y. and X.J.; writing-review and editing, C.Y. and X.J.; supervision, C.Y.; funding acquisition, C.Y. and C.W. All authors have read and agreed to the published version of the manuscript.

Funding: This work was supported by National Natural Science Fund of the People's Republic of China (NSFC) (31970072), by Major Projects in Basic and Applied Research of Guangdong Province Office of Education (2017KZDXM074) and by Shenzhen Science and technology innovation committee project (JCYJ20180507182239272).

Institutional Review Board Statement: This study did not involve humans or animals.

Informed Consent Statement: This study did not involve humans.

Data Availability Statement: The whole dataset of RNA-seq has been deposited to GEO with the accession number of GSE182531. All of the data is contained within the article and the supplementary materials.

Acknowledgments: We thank all members in the You lab for discussion and technical support.

Conflicts of Interest: The authors declare no conflict of interest.

\section{References}

1. Moon, K.; Gottesman, S. A PhoQ/P-regulated small RNA regulates sensitivity of Escherichia coli to antimicrobial peptides. Mol. Microbiol. 2009, 74, 1314-1330. [CrossRef] [PubMed]

2. Parker, A.; Cureoglu, S.; De Lay, N.; Majdalani, N.; Gottesman, S. Alternative pathways for Escherichia coli biofilm formation revealed by sRNA overproduction. Mol. Microbiol. 2017, 105, 309-325. [CrossRef]

3. Sedlyarova, N.; Shamovsky, I.; Bharati, B.K.; Epshtein, V.; Chen, J.; Gottesman, S.; Schroeder, R.; Nudler, E. sRNA-Mediated Control of Transcription Termination in E. coli. Cell 2016, 167, 111-121.e13. [CrossRef] [PubMed]

4. Khan, M.A.; Durica-Mitic, S.; Gopel, Y.; Heermann, R.; Gorke, B. Small RNA-binding protein RapZ mediates cell envelope precursor sensing and signaling in Escherichia coli. EMBO J. 2020, 39, e103848. [CrossRef]

5. Argaman, L.; Hershberg, R.; Vogel, J.; Bejerano, G.; Wagner, E.G.H.; Margalit, H.; Altuvia, S. Novel small RNA-encoding genes in the intergenic regions of Escherichia coli. Curr. Biol. 2001, 11, 941-950. [CrossRef]

6. Gottesman, S. The small RNA regulators of Escherichia coli: Roles and mechanisms. Annu. Rev. Microbiol. 2004, 58, 303-328. [CrossRef]

7. Hershberg, R.; Altuvia, S.; Margalit, H. A survey of small RNA-encoding genes in Escherichia coli. Nucleic Acids Res. 2003, 31, 1813-1820. [CrossRef] [PubMed]

8. Majdalani, N.; Vanderpool, C.K.; Gottesman, S. Bacterial small RNA regulators. Crit. Rev. Biochem. Mol. Biol. 2005, 40, 93-113. [CrossRef]

9. Storz, G.; Altuvia, S.; Wassarman, K.M. An abundance of RNA regulators. Annu. Rev. Biochem. 2005, 74, 199-217. [CrossRef]

10. Vogel, J.; Papenfort, K. Small non-coding RNAs and the bacterial outer membrane. Curr. Opin. Microbiol. 2006, 9, 605-611. [CrossRef]

11. Wagner, E.G.H.; Flärdh, K. Antisense RNAs everywhere? TRENDS Genet. 2002, 18, 223-226. [CrossRef]

12. Wassarman, K.M. Small RNAs in bacteria: Diverse regulators of gene expression in response to environmental changes. Cell 2002, 109, 141-144. [CrossRef]

13. Sharma, C.M.; Darfeuille, F.; Plantinga, T.H.; Vogel, J. A small RNA regulates multiple ABC transporter mRNAs by targeting C/A-rich elements inside and upstream of ribosome-binding sites. Genes Dev. 2007, 21, 2804-2817. [CrossRef] [PubMed]

14. Melamed, S.; Peer, A.; Faigenbaum-Romm, R.; Gatt, Y.E.; Reiss, N.; Bar, A.; Altuvia, Y.; Argaman, L.; Margalit, H. Global Mapping of Small RNA-Target Interactions in Bacteria. Mol. Cell 2016, 63, 884-897. [CrossRef] [PubMed]

15. Pulvermacher, S.C.; Stauffer, L.T.; Stauffer, G.V. Role of the sRNA GcvB in regulation of cycA in Escherichia coli. Microbiology 2009, 155, 106-114. [CrossRef] [PubMed]

16. Sharma, C.M.; Papenfort, K.; Pernitzsch, S.R.; Mollenkopf, H.J.; Hinton, J.C.; Vogel, J. Pervasive post-transcriptional control of genes involved in amino acid metabolism by the Hfq-dependent GcvB small RNA. Mol. Microbiol. 2011, 81, 1144-1165. [CrossRef] [PubMed]

17. Wright, P.R.; Georg, J.; Mann, M.; Sorescu, D.A.; Richter, A.S.; Lott, S.; Kleinkauf, R.; Hess, W.R.; Backofen, R. CopraRNA and IntaRNA: Predicting small RNA targets, networks and interaction domains. Nucleic Acids Res. 2014, 42, W119-W123. [CrossRef]

18. Ernst, D.C.; Downs, D.M. 2-Aminoacrylate Stress Induces a Context-Dependent Glycine Requirement in ridA Strains of Salmonella enterica. J. Bacteriol. 2016, 198, 536-543. [CrossRef] [PubMed] 
19. Rossi, C.C.; Bosse, J.T.; Li, Y.; Witney, A.A.; Gould, K.A.; Langford, P.R.; Bazzolli, D.M. A computational strategy for the search of regulatory small RNAs in Actinobacillus pleuropneumoniae. RNA 2016, 22, 1373-1385. [CrossRef]

20. Urbanowski, M.L.; Stauffer, L.T.; Stauffer, G.V. The gcvB gene encodes a small untranslated RNA involved in expression of the dipeptide and oligopeptide transport systems in Escherichia coli. Mol. Microbiol. 2000, 37, 856-868. [CrossRef]

21. Lalaouna, D.; Eyraud, A.; Devinck, A.; Prevost, K.; Masse, E. GcvB small RNA uses two distinct seed regions to regulate an extensive targetome. Mol. Microbiol. 2019, 111, 473-486. [CrossRef]

22. Modi, S.R.; Camacho, D.M.; Kohanski, M.A.; Walker, G.C.; Collins, J.J. Functional characterization of bacterial sRNAs using a network biology approach. Proc. Natl. Acad. Sci. USA 2011, 108, 15522-15527. [CrossRef] [PubMed]

23. Pulvermacher, S.C.; Stauffer, L.T.; Stauffer, G.V. The small RNA GcvB regulates sstT mRNA expression in Escherichia coli. J. Bacteriol. 2009, 191, 238-248. [CrossRef]

24. Lee, H.J.; Gottesman, S. sRNA roles in regulating transcriptional regulators: Lrp and SoxS regulation by sRNAs. Nucleic Acids Res. 2016, 44, 6907-6923. [CrossRef]

25. Tani, T.H.; Khodursky, A.; Blumenthal, R.M.; Brown, P.O.; Matthews, R.G. Adaptation to famine: A family of stationary-phase genes revealed by microarray analysis. Proc. Natl. Acad. Sci. USA 2002, 99, 13471-13476. [CrossRef]

26. Coornaert, A.; Chiaruttini, C.; Springer, M.; Guillier, M. Post-transcriptional control of the Escherichia coli PhoQ-PhoP twocomponent system by multiple sRNAs involves a novel pairing region of GcvB. PLoS Genet. 2013, 9, e1003156. [CrossRef] [PubMed]

27. Kato, A.; Tanabe, H.; Utsumi, R. Molecular characterization of the PhoP-PhoQ two-component system in Escherichia coli K-12: Identification of extracellular Mg2+-responsive promoters. J. Bacteriol. 1999, 181, 5516-5520. [CrossRef]

28. Minagawa, S.; Ogasawara, H.; Kato, A.; Yamamoto, K.; Eguchi, Y.; Oshima, T.; Mori, H.; Ishihama, A.; Utsumi, R. Identification and molecular characterization of the Mg2+ stimulon of Escherichia coli. J. Bacteriol. 2003, 185, 3696-3702. [CrossRef]

29. Zwir, I.; Shin, D.; Kato, A.; Nishino, K.; Latifi, T.; Solomon, F.; Hare, J.M.; Huang, H.; Groisman, E.A. Dissecting the PhoP regulatory network of Escherichia coli and Salmonella enterica. Proc. Natl. Acad. Sci. USA 2005, 102, 2862-2867. [CrossRef]

30. Jorgensen, M.G.; Nielsen, J.S.; Boysen, A.; Franch, T.; Moller-Jensen, J.; Valentin-Hansen, P. Small regulatory RNAs control the multi-cellular adhesive lifestyle of Escherichia coli. Mol. Microbiol. 2012, 84, 36-50. [CrossRef] [PubMed]

31. Römling, U.; Bian, Z.; Hammar, M.; Sierralta, W.D.; Normark, S. Curli fibers are highly conserved between Salmonella typhimurium and Escherichia coli with respect to operon structure and regulation. J. Bacteriol. 1998, 180, 722-731. [CrossRef] [PubMed]

32. Jin, Y.; Watt, R.M.; Danchin, A.; Huang, J.D. Small noncoding RNA GcvB is a novel regulator of acid resistance in Escherichia coli. BMC Genom. 2009, 10, 165. [CrossRef]

33. Barreto, B.; Rogers, E.; Xia, J.; Frisch, R.L.; Richters, M.; Fitzgerald, D.M.; Rosenberg, S.M. The Small RNA GcvB Promotes Mutagenic Break Repair by Opposing the Membrane Stress Response. J. Bacteriol. 2016, 198, 3296-3308. [CrossRef] [PubMed]

34. Chen, H.; Previero, A.; Deutscher, M.P. A novel mechanism of ribonuclease regulation: GcvB and Hfq stabilize the mRNA that encodes RNase BN/Z during exponential phase. J. Biol. Chem. 2019, 294, 19997-20008. [CrossRef]

35. Roberts, A.; Pimentel, H.; Trapnell, C.; Pachter, L. Identification of novel transcripts in annotated genomes using RNA-Seq. Bioinformatics 2011, 27, 2325-2329. [CrossRef]

36. Li, Z.; Pan, Q.; Xiao, Y.; Fang, X.; Shi, R.; Fu, C.; Danchin, A.; You, C. Deciphering global gene expression and regulation strategy in Escherichia coli during carbon limitation. Microb. Biotechnol. 2019, 12, 360-376. [CrossRef] [PubMed]

37. Pan, Q.; Li, Z.; Ju, X.; Hou, C.; Xiao, Y.; Shi, R.; Fu, C.; Danchin, A.; You, C. Escherichia coli segments its controls on carbondependent gene expression into global and specific regulations. Microb. Biotechnol. 2021, 14, 1084-1106. [CrossRef]

38. Anand, A.; Chen, K.; Catoiu, E.; Sastry, A.V.; Olson, C.A.; Sandberg, T.E.; Seif, Y.; Xu, S.; Szubin, R.; Yang, L. OxyR is a convergent target for mutations acquired during adaptation to oxidative stress-prone metabolic states. Mol. Biol. Evol. 2020, 37, 660-667. [CrossRef]

39. Storz, G.; Tartaglia, L.A.; Ames, B.N. Transcriptional regulator of oxidative stress-inducible genes: Direct activation by oxidation. Science 1990, 248, 189-194. [CrossRef]

40. You, C.; Okano, H.; Hui, S.; Zhang, Z.; Kim, M.; Gunderson, C.W.; Wang, Y.P.; Lenz, P.; Yan, D.; Hwa, T. Coordination of bacterial proteome with metabolism by cyclic AMP signalling. Nature 2013, 500, 301-306. [CrossRef]

41. Datsenko, K.A.; Wanner, B.L. One-step inactivation of chromosomal genes in Escherichia coli K-12 using PCR products. Proc. Natl. Acad. Sci. USA 2000, 97, 6640-6645. [CrossRef]

42. Lyons, E.; Freeling, M.; Kustu, S.; Inwood, W. Using genomic sequencing for classical genetics in E. coli K12. PLoS ONE 2011, 6, e16717. [CrossRef] [PubMed]

43. Toledano, M.B.; Kullik, I.; Trinh, F.; Baird, P.T.; Schneider, T.D.; Storz, G. Redox-dependent shift of OxyR-DNA contacts along an extended DNA-binding site: A mechanism for differential promoter selection. Cell 1994, 78, 897-909. [CrossRef]

44. Trapnell, C.; Williams, B.A.; Pertea, G.; Mortazavi, A.; Kwan, G.; van Baren, M.J.; Salzberg, S.L.; Wold, B.J.; Pachter, L. Transcript assembly and quantification by RNA-Seq reveals unannotated transcripts and isoform switching during cell differentiation. Nat. Biotechnol. 2010, 28, 511-515. [CrossRef] [PubMed]

45. Van der Woude, M.W.; Henderson, I.R. Regulation and function of Ag43 (flu). Annu. Rev. Microbiol. 2008, 62, 153-169. [CrossRef]

46. Laganenka, L.; Colin, R.; Sourjik, V. Chemotaxis towards autoinducer 2 mediates autoaggregation in Escherichia coli. Nat. Commun. 2016, 7, 12984. [CrossRef] [PubMed] 
47. Cremer, J.; Honda, T.; Tang, Y.; Wong-Ng, J.; Vergassola, M.; Hwa, T. Chemotaxis as a navigation strategy to boost range expansion. Nature 2019, 575, 658-663. [CrossRef]

48. Berg, H.C. The rotary motor of bacterial flagella. Annu. Rev. Biochem. 2003, 72, 19-54. [CrossRef]

49. Henderson, I.R.; Owen, P. The major phase-variable outer membrane protein of Escherichia coli structurally resembles the immunoglobulin A1 protease class of exported protein and is regulated by a novel mechanism involving Dam and OxyR. J. Bacteriol. 1999, 181, 2132-2141. [CrossRef]

50. Rodríguez-Rojas, A.; Kim, J.J.; Johnston, P.R.; Makarova, O.; Eravci, M.; Weise, C.; Hengge, R.; Rolff, J. Non-lethal exposure to $\mathrm{H}_{2} \mathrm{O}_{2}$ boosts bacterial survival and evolvability against oxidative stress. PLoS Genet. 2020, 16, e1008649. [CrossRef]

51. Marcén, M.; Ruiz, V.; Serrano, M.J.; Condón, S.; Mañas, P. Oxidative stress in E. coli cells upon exposure to heat treatments. Int. J. Food Microbiol. 2017, 241, 198-205. [CrossRef] [PubMed]

52. Storz, G.; Vogel, J.; Wassarman, K.M. Regulation by small RNAs in bacteria: Expanding frontiers. Mol. Cell 2011, 43, 880-891. [CrossRef] [PubMed]

53. Van Acker, H.; Coenye, T. The Role of Reactive Oxygen Species in Antibiotic-Mediated Killing of Bacteria. Trends Microbiol. 2017, 25, 456-466. [CrossRef] [PubMed] 